\title{
ACS \\ Are Aqueous Biphasic Systems Composed of Deep Eutectic Solvents Ternary or Quaternary Systems?
}

\author{
Helena Passos, Daniel J. P. Tavares, Ana M. Ferreira, Mara G. Freire, and João A. P. Coutinho* \\ CICECO-Aveiro Institute of Materials, Department of Chemistry, University of Aveiro, 3810193 Aveiro, Portugal
}

Supporting Information

ABSTRACT: Deep eutectic solvents (DES) have emerged in the past few years as a new class of solvents with promising applications in several fields. In the present work, the application of DES (formed by binary mixtures of cholinium chloride and carboxylic acids or urea) as phase forming components of aqueous biphasic systems (ABS) is inves tigated. The mechanisms associated with the phases demixing of ABS composed of DES, as well as the DES stability in aqueous solutions, are investigated to address the critical question whether DES based $\mathrm{ABS}$ are in fact ternary or quaternary mixtures. It is shown that the DES integrity is destroyed in ABS by the disruption of the hydrogen bonding interactions of the complex (a result of the isolated components preferential solvation by water), and as confirmed by a nonstoichiometric partition of the DES components between the coexisting phases. As a result, there are no "real" DES based $\mathrm{ABS}$; instead, there is the formation of ABS composed of four components, where the carboxylic acid used as the hydrogen bond donor species seems to act as an additive. Finally, it is shown that these ABS have an outstanding potential to be used in extraction processes, as it is here demonstrated with the complete separation of two dyes. However, the volatile nature of short chain carboxylic acids and the nonstoichiometric partition of the DES components in ABS make the development of recovery and recycling steps more difficult to accomplish.

KEYWORDS: Deep eutectic solvents, Hydrogen bonding, Aqueous biphasic systems, Ternary/quaternary systems, Liquid-liquid extraction, Selective separation

\section{INTRODUCTION}

Deep eutectic solvents (DES) were introduced in 2003, when Abbott and co workers ${ }^{1}$ demonstrated the possibility of producing a liquid solvent at room temperature by mixing two solid starting materials with considerably higher melting points (e.g., urea and cholinium chloride $\left(\left[\mathrm{N}_{111(2 \mathrm{OH})}\right] \mathrm{Cl}\right)$, with melting temperatures of 133 and $302{ }^{\circ} \mathrm{C}$, respectively). After this proof of concept, the number of works concerning the understanding of the underlying molecular level scenario, their physical and chemical properties, as well as their applications as alternative solvents, increased significantly. ${ }^{2-4}$

The formation of DES results from the formation of strong hydrogen bonds between the two starting materials, namely, a hydrogen bond donor (HBD) and a hydrogen bond acceptor (HBA). The formation of ion-HBD complexes leads to a lower entropic difference of the phase transition and to the further depression of the freezing temperature. ${ }^{5-7}$ The first reported DES (composed of $\left[\mathrm{N}_{111(2 \mathrm{OH})}\right] \mathrm{Cl}$ and urea) ${ }^{1}$ remains the most widely investigated. However, DES can be formed by mixing other substituted tetralkylammonium or phosphonium salts with a HBD, such as amines, carboxylic acids, and carbohydrates, among others. ${ }^{8-10}$

Many DES share some of the unique characteristics of ionic liquids (ILs), namely, a low volatility, high conductivity, wide liquid temperature range, and high solvation ability for a large number of compounds. ${ }^{3,4}$ DES are also able to overcome some of the disadvantages related to ILs. They are easier to prepare, by a simple mixture of the starting materials at moderate temperatures, without requiring a reaction step. Furthermore, the addition of an agent able to disrupt hydrogen bonding interactions can lead to the recovery of at least one of the initial compounds. ${ }^{3,4,11,12}$ The starting materials are usually cheaper, toxicologically well characterized, and often derived from renewable resources, which results in low cost and more environmentally friendly products. ${ }^{3,4,11,12}$ As in ILs, innumer ous combinations of the starting materials can be attempted, and therefore, DES may also be classified as "designer solvents". Since DES have fewer restrictions in terms of stoichiometry, their properties and phase behavior can be tuned by changing the ratio of their components, thus adding one more degree of freedom to their design. ${ }^{3,4,11,12}$ Although reports regarding the applications of DES are still limited, a reasonable number of studies have shown the potential of DES as alternative solvents in electrochemistry, catalysis, synthesis, and separation processes. $3,4,13-15$

Received: March 8, 2016

Revised: April 2, 2016 
In the past decade, aqueous biphasic systems (ABS) composed of ILs and a wide number of salts, carbohydrates, polymers, or amino acids have been extensively studied for the extraction and purification of bioactive compounds. ${ }^{16} \mathrm{IL}$ based ABS lead to remarkable extraction efficiencies and selectivities by a proper tailoring of their phases' polarities and affinities. ${ }^{16}$ Albeit scarcely investigated, the potential of DES as phase forming components of $\mathrm{ABS}$ was recently reported by $\mathrm{Xu}$ and co workers. ${ }^{1,18}$ Yet, those pioneering phenomenological results did not comprise the mechanisms associated with the coexisting phases demixing and the stability of the HBD:HBA complex in aqueous media. Only "ternary" phase diagrams for each ABS were reported, and their applications to the extraction of proteins were presented. ${ }^{17,18}$ Whether DES in the form of a HBD:HBA complex will form a ternary system, as in common $\mathrm{ABS}$, or the alleged DES based ABS is a quaternary system that phase separates with a nonstoichiometric partition of the HBD and HBA species between the two phases remains an open question. In this context, the present work aims at shedding light on this subject. For this purpose, novel ABS composed of water, poly(propylene) glycol with an average molecular weight of $400 \mathrm{~g} \mathrm{~mol}^{-1}$ (PPG 400), and several DES formed by $\left[\mathrm{N}_{111(2 \mathrm{OH})}\right] \mathrm{Cl}$ and carboxylic acids or urea were investigated. PPG 400 was selected for its good ability to form $\mathrm{ABS}^{19,20}$ and because the use of polymers instead of ILs or salts to form DES based ABS prevents the introduction of other ionic species into solution and possible ion exchange between the two phases. The studied DES allow the analysis of the effect of the urea or carboxylic acid: $\left[\mathrm{N}_{111(2 \mathrm{OH})}\right] \mathrm{Cl}$ ratio and the impact of the HBD species on their ability for the creation of ABS, as well as to infer on their nonstoichiometric partition between the coexisting phases. The phase formation capability of these systems is also herein compared with ABS formed by $\left[\mathrm{N}_{111(2 \mathrm{OH})}\right]$ based ILs, with anions corresponding to the investigated acids, and PPG 400. Finally, the application of these systems for the selective separation of dyes is investigated to ascertain on their potential applicability.

\section{EXPERIMENTAL SECTION}

Materials. The determination of the liquid-liquid phase diagrams was performed using aqueous solutions of PPG with an average molecular weight of $400 \mathrm{~g} \mathrm{~mol}^{-1}$ (from Sigma Aldrich, Germany) and individual aqueous solutions of DES, prepared by us, using the following components: $\left[\mathrm{N}_{111(2 \mathrm{OH})}\right] \mathrm{Cl}(98 \mathrm{wt} \%$ pure from Sigma Aldrich, Germany), glycolic acid ( $>99$ wt \% pure from Sigma Aldrich, Germany), acetic acid ( $>99$ wt \% pure from Sigma Aldrich, Germany), lactic acid (88-92 wt \% pure from Riedel de Haën, Germany), citric acid tetrahydrated (100\% pure from Fisher Scientific, USA), and urea (99.0-100.5\% pure from Panreac, Spain). All components used on the DES preparation were dried under vacuum $(10 \mathrm{~Pa})$ at room temperature for a minimum of $24 \mathrm{~h}$. The cholinium based ILs used on the dyes' selective extraction were $\left[\mathrm{N}_{111(2 \mathrm{OH})}\right] \mathrm{Cl}$, cholinium dihydrogen citrate, $\left[\mathrm{N}_{111(2 \mathrm{OH})}\right][\mathrm{DHC}]$ (98 wt \% pure from Sigma Aldrich, Germany), cholinium acetate, $\left[\mathrm{N}_{11(2 \mathrm{OH})}\right][\mathrm{Ac}]$ (98 wt \% pure from Iolitec, Germany), cholinium glycolate, $\left[\mathrm{N}_{111(2 \mathrm{OH})}\right][\mathrm{Gly}]$ (97 wt $\%$ pure and synthesized by us), and cholinium lactate, $\left[\mathrm{N}_{111(2 \mathrm{OH})}\right]$ [Lac] (99 wt \% pure and synthesized by us). The ILs synthesized by us were prepared according to well established protocols. ${ }^{21,22}$ The required precursors were commercially acquired, namely, cholinium hydroxide $\left[\mathrm{N}_{111(2 \mathrm{OH})}\right][\mathrm{OH}]$ (40 wt \% in methanol) from Sigma Aldrich (Germany) and glycolic acid and lactic acid as described before. After the synthesis and before use, all ILs were purified and dried for a minimum of $24 \mathrm{~h}$ at constant agitation, at a moderate temperature $\left(\sim 70{ }^{\circ} \mathrm{C}\right)$ under vacuum $(10 \mathrm{~Pa})$. The extracted dyes were Sudan III ( $>99$ wt \% pure) from Merck (Germany) and pigment blue 29 (PB29) obtained from Holliday Pigments (France). The chemical structures of studied DES, ILs, PPG, and dyes are presented in the Supporting Information, Figure S1. The water used was double distilled, passed through a reverse osmosis system, and further treated with a Milli Q plus 185 apparatus.

DES Preparation. For the preparation of DES, both the hydrogen bond donor (carboxylic acids or urea) and acceptor $\left(\left[\mathrm{N}_{111(2 \mathrm{OH})}\right] \mathrm{Cl}\right)$ species were added gravimetrically within $\pm 10^{-4}$ g to closed vials, at three different mole ratios, $1: 2,1: 1$, and 2:1 of carboxylic acid: $\left[\mathrm{N}_{111(2 \mathrm{OH})}\right] \mathrm{Cl}$ and urea: $\left[\mathrm{N}_{111(2 \mathrm{OH})}\right] \mathrm{Cl}$, and heated in an oil bath with constant agitation. The maximum temperature reached was $60{ }^{\circ} \mathrm{C}$ for the DES composed of acetic acid and $100{ }^{\circ} \mathrm{C}$ for DES composed of glycolic acid, lactic acid, and urea. For the preparation of the citric acid based DES, higher temperatures, close to $120^{\circ} \mathrm{C}$, were required until the formation of a transparent liquid. After the formation of a liquid, the mixture was maintained for $1 \mathrm{~h}$ at the final temperature and was then cooled down to room temperature. All the procedure was executed under an inert atmosphere. The water content of the DES constituents was measured using a Metrohm 831 Karl Fischer coulometer that was taken into consideration during the preparation of each mixture. The final physical state (liquid or wet solid) and composition of the synthesized DES at room temperature are described in the Supporting Information, Tables S1 and S2, respectively.

Phase Diagrams and Tie-Lines. The solubility curves were determined through the cloud point titration method ${ }^{23,24}$ at $25{ }^{\circ} \mathrm{C}$ $\left( \pm 1{ }^{\circ} \mathrm{C}\right)$ and atmospheric pressure. Aqueous solutions of PPG at approximately $80 \mathrm{wt} \%$ and aqueous solutions of the different DES at $75 \mathrm{wt} \%$ were prepared and used for the determination of the binodal curves. Repetitive dropwise addition, under constant stirring, of the aqueous DES solution to the aqueous solutions of PPG was carried out until the detection of a cloudy (biphasic) solution, followed by the dropwise addition of ultrapure water until the finding of a monophasic region (clear and limpid solution). The ternary system compositions were determined by weight quantification within $\pm 10^{-4} \mathrm{~g}$.

The experimental binodal curves were fitted by eq $1 .^{23}$

$$
[\mathrm{PPG}]=A \mathrm{e}^{\left[\left(B[\mathrm{DES}]^{0.5}\right)-\left(\mathrm{C}[\mathrm{DES}]^{3}\right)\right]}
$$

Here [PPG] and [DES] are the PPG and DES weight fraction percentages, respectively, and $A, B$, and $C$ are constants obtained by the regression of the experimental binodal data. Further details on the determination of the tie lines (TLs) and tie line length (TLL) are given in the Supporting Information.

The $\mathrm{pH}$ values $( \pm 0.02)$ of the PPG and "DES" rich aqueous phases were measured at $(25 \pm 1){ }^{\circ} \mathrm{C}$ using a Mettler Toledo SevenMulti dual $\mathrm{pH}$ meter.

DES Stability in Aqueous Media. To evaluate if the HBD $\left[\mathrm{N}_{111(2 \mathrm{OH})}\right] \mathrm{Cl}$ hydrogen bonding interactions are maintained when DES are dissolved in water or in the ABS formation, the mole ratio between each carboxylic acid or urea and the cholinium cation in each phase of the corresponding $\mathrm{ABS}$ was determined by ${ }^{1} \mathrm{H}$ nuclear magnetic resonance (NMR), in solution and neat, respectively, using a Bruker Avance 300 at $300.13 \mathrm{MHz}$, with deuterium oxide $\left(\mathrm{D}_{2} \mathrm{O}\right)$ as solvent and trimethylsilyl propanoic acid (TSP) as the internal reference. For this, individual ABS composed of PPG + DES + water at the biphasic region were gravimetrically prepared within $\pm 10^{-4} \mathrm{~g}$, vigorously agitated, and centrifuged at $3500 \mathrm{rpm}$ for $30 \mathrm{~min}$ at $(25 \pm$ 1) ${ }^{\circ} \mathrm{C}$, in order to reach the equilibrium and a complete separation of the coexisting phases. Samples of each phase were then taken for the quantification of each carboxylic acid or urea and the cholinium cation by ${ }^{1} \mathrm{H}$ NMR.

Selective Extraction of Textile Dyes. Two textile dyes, Sudan III and PB29, were studied as model molecules to demonstrate the potential application of DES based ABS. A ternary mixture with a common composition, and within the biphasic region, was prepared with 21 wt \% of DES, 40 wt \% of PPG, and 39 wt \% of water with the exception of the ABS constituted by the following DES: 1:1 and 2:1 of citric acid: $\left[\mathrm{N}_{111(2 \mathrm{OH})}\right] \mathrm{Cl}$. With these two systems, the following mixture point was used: $25 \mathrm{wt} \%$ of DES $+50 \mathrm{wt} \%$ of PPG +25 wt $\%$ 

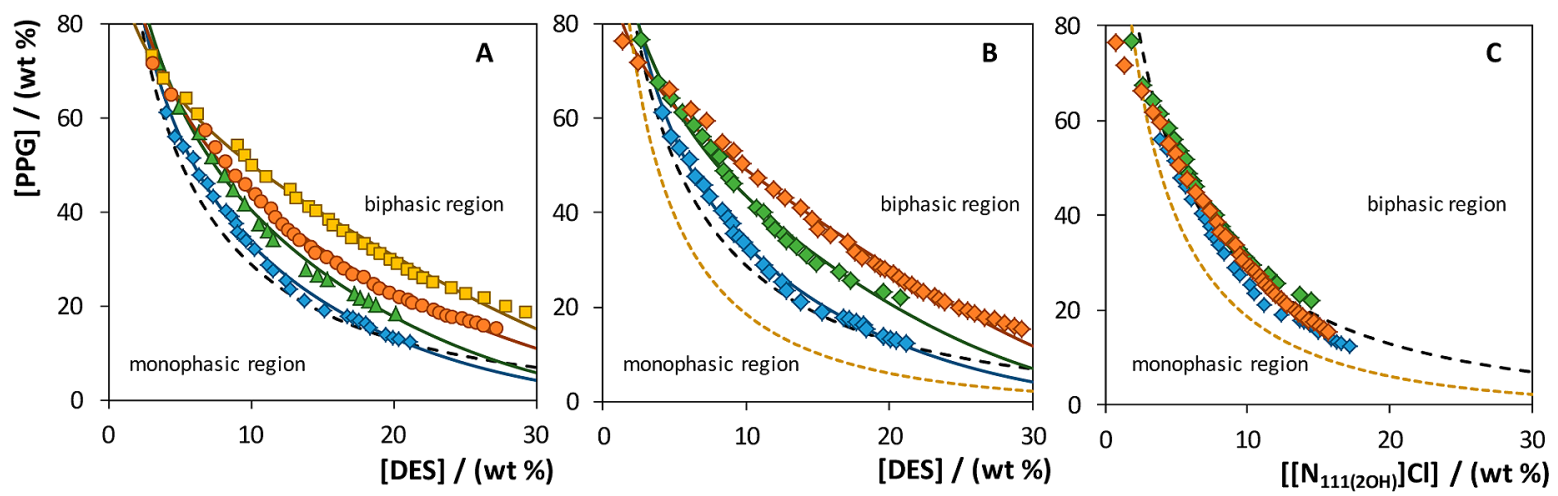

Figure 1. Phase diagrams of DES based ABS at $25^{\circ} \mathrm{C}$. (A) Carboxylic acid nature effect on ABS formation: DES constituted by 1:2 mol proportion of acetic acid: $\left[\mathrm{N}_{111(2 \mathrm{OH})}\right] \mathrm{Cl}$ (blue $\diamond$ ), glycolic acid: $\left[\mathrm{N}_{111(2 \mathrm{OH})}\right] \mathrm{Cl}$ (green $\boldsymbol{\Delta}$ ), lactic acid: $\left[\mathrm{N}_{111(2 \mathrm{OH})}\right] \mathrm{Cl}$ (orange $\boldsymbol{\bullet}$ ), and citric acid: $\left[\mathrm{N}_{111(2 \mathrm{OH})}\right] \mathrm{Cl}$ (yellow -); fitting of the binodal data by eq $1(-)$; $\left[\mathrm{N}_{111(2 \mathrm{OH})}\right] \mathrm{Cl}$ based ABS binodal curve ( ). (B) Carboxylic acid concentration effect on ABS formation: DES composed of acetic acid: $\left[\mathrm{N}_{111(2 \mathrm{OH})}\right] \mathrm{Cl}$ mole proportion of 1:2 (blue $\left.\boldsymbol{\bullet}\right), 1: 1$ (green $\boldsymbol{\Delta}$ ), and 2:1 (orange $\boldsymbol{\nabla}$ ); fitting of the binodal data by eq $1(-)$; $\left[\mathrm{N}_{111(2 \mathrm{OH})}\right] \mathrm{Cl}$ based ABS binodal curve ( ); $\left[\mathrm{N}_{111(2 \mathrm{OH})}\right][$ Ace] based ABS binodal curve (yellow ). (C) Representation of the binodal curves of acetic acid: $\left[\mathrm{N}_{111(2 \mathrm{OH})}\right] \mathrm{Cl}$ based $\mathrm{ABS}$ as a function of the $\left[\mathrm{N}_{111(2 \mathrm{OH})}\right] \mathrm{Cl}$ concentration: $\mathrm{DES}$ composed of acetic acid: $\left[\mathrm{N}_{111(2 \mathrm{OH})}\right] \mathrm{Cl}$ mole proportion of 1:2 (blue $\diamond), 1: 1$ (green $\diamond$ ), and 2:1 (orange $\diamond$ ); $\left[\mathrm{N}_{111(2 \mathrm{OH})}\right]$ Cl based ABS binodal curve $\left(\quad\right.$ ); $\left[\mathrm{N}_{111(2 \mathrm{OH})}\right][\mathrm{Ac}]$ based $\mathrm{ABS}$ binodal curve (yellow ).

of $\mathrm{H}_{2} \mathrm{O}$. In each system, with a total weight of $3 \mathrm{~g}$, a small amount of each dye $(\approx 0.30 \mathrm{mg})$ was added. After the total dissolution of both dyes, each mixture was centrifuged at $1500 \mathrm{rpm}$ for $10 \mathrm{~min}$ at $(25 \pm 1)$ ${ }^{\circ} \mathrm{C}$ to achieve the complete partitioning of each dye between the two phases.

After a careful separation of both phases, the quantification of each dye in the two phases was carried by UV-vis spectroscopy, using a synergy/HT microplate reader, at a wavelength of $348 \mathrm{~nm}$ for Sudan III and $725 \mathrm{~nm}$ for PB 29. At least three individual experiments were performed in order to determine the average in the extraction efficiency, as well as the respective standard deviations. The interference of the polymer and DES with the quantification method was also taken into account, and blank control samples were always employed. The percentage extraction efficiency of Sudan III is defined as the percentage ratio between the amount of dye in the PPG aqueous rich phase and that in the total mixture. Similarly, the percentage extraction efficiency of PB29 is defined as the percentage ratio between the amount of dye in the "DES" aqueous rich phase and that in the total mixture.

\section{RESULTS AND DISCUSSION}

A total of 15 DES formed by $\left[\mathrm{N}_{111(2 \mathrm{OH})}\right] \mathrm{Cl}$, as the HBA, and four carboxylic acids as the HBD, namely, lactic, glycolic, citric and acetic acids, or urea, at three mole composition ratios (2:1, $1: 1$, and $1: 2$ ), were prepared. The liquid-liquid phase diagrams of some ABS composed of DES + PPG $400+\mathrm{H}_{2} \mathrm{O}$ are depicted in Figure 1. For all phase diagrams, the biphasic region is located above the binodal curve, and the monophasic region is localized below. The detailed experimental weight fraction data and the representation of the phase diagrams for the remaining DES based ABS are presented in the Supporting Information, along with the compositions of the coexisting phases (tie lines). In the studied ABS, the top phase corresponds to the PPG rich phase, while the bottom phase is mainly composed of an aqueous solution enriched in DES.

Figure $1 \mathrm{~A}$ allows the evaluation of the effect of the carboxylic acid nature on the ABS formation ability. It is well established that the higher the ion's ability to create hydration complexes is the easier the formation of salt-polymer or IL-salt ABS is. ${ }^{16,25}$ The DES ability to form ABS is in the following order: acetic acid: $\left[\mathrm{N}_{111(2 \mathrm{OH})}\right] \mathrm{Cl}>$ glycolic acid: $\left[\mathrm{N}_{111(2 \mathrm{OH})}\right] \mathrm{Cl}>$ lactic acid: $\left[\mathrm{N}_{111(2 \mathrm{OH})}\right] \mathrm{Cl}>$ citric acid: $\left[\mathrm{N}_{111(2 \mathrm{OH})}\right] \mathrm{Cl}$. In a comparison of the DES capability to form ABS with the corresponding
$\left[\mathrm{N}_{111(2 \mathrm{OH})}\right]$ based ILs $\left(\left[\mathrm{N}_{111(2 \mathrm{OH})}\right][\mathrm{Gly}] \sim\left[\mathrm{N}_{111(2 \mathrm{OH})}\right][\mathrm{Ac}]>\right.$ $\left.\left[\mathrm{N}_{111(2 \mathrm{OH})}\right][\mathrm{Lac}] \sim\left[\mathrm{N}_{111(2 \mathrm{OH})}\right] \mathrm{Cl}>\left[\mathrm{N}_{111(2 \mathrm{OH})}\right][\mathrm{DHC}]\right),{ }^{26}$ it is possible to identify a similar trend. According to the $\left[\mathrm{N}_{111(2 \mathrm{OH})}\right]$ $\mathrm{Cl}$ position in this trend, it is however evident that there is a stronger aptitude of the $\left[\mathrm{N}_{111(2 \mathrm{OH})}\right]$ based ILs to form ABS (cf. the Supporting Information). In general, and as represented in Figure 1A, it seems that carboxylic acids with shorter alkyl side chains have a higher liquid-liquid demixing ability. Never theless, when the weight fraction of the several acids is not considered, a different scenario emerges, with a nonsignificant impact of the acid nature as discussed below.

Figure 1B depicts the carboxylic acid concentration effect, where an increase of the acid content leads to a decrease on the area of the biphasic regime. This behavior is always observed and appears to be independent of the acid nature. Furthermore, with consideration of the eutectic point of the DES studied ( 2:1 for acetic and lactic acid based DES, 1:1 for glycolic acid: $\left[\mathrm{N}_{111(2 \mathrm{OH})}\right] \mathrm{Cl} \mathrm{DES}$, and $1: 2$ for citric acid: $\left[\mathrm{N}_{111(2 \mathrm{OH})}\right] \mathrm{Cl}$ DES $),{ }^{11}$ it is clear that the application of an eutectic mixture does not change this trend. It was previously reported that $\left[\mathrm{N}_{111(2 \mathrm{OH})}\right] \mathrm{Cl}$ is the salting out agent in PPG based ABS. ${ }^{26}$ As shown in Figure 1A, the presence of a non salting out species, such as a carboxylic acid, seems to decrease the ability of ABS formation by $\left[\mathrm{N}_{111(2 \mathrm{OH})}\right] \mathrm{Cl}$. However, when the binodal curves are presented as a function of the isolated $\left[\mathrm{N}_{111(2 \mathrm{OH})}\right] \mathrm{Cl}$ concentration, Figure $1 \mathrm{C}$, there is an almost complete superposition of the solubility curves. This pattern supports the vision of a mechanism of salting out of $\left[\mathrm{N}_{111(2 \mathrm{OH})}\right] \mathrm{Cl}$ over PPG in aqueous media, with the carboxylic acid contributing with a minor effect on the ability of ABS formation.

Although the formation of $\mathrm{ABS}$ using DES is unquestionable, there remains the major question of whether the carboxylic acid: $\left[\mathrm{N}_{111(2 \mathrm{OH})}\right] \mathrm{Cl}$ DES complexes are maintained when dissolved in aqueous media (for ABS formation). To gather novel insights on this matter, ${ }^{1} \mathrm{H}$ NMR spectra of both phases were acquired to evaluate the content and ratio between each acid and $\left[\mathrm{N}_{111(2 \mathrm{OH})}\right] \mathrm{Cl}$. Examples of these spectra are provided in the Supporting Information.

Figure 2 depicts the $\mathrm{HBD}:\left[\mathrm{N}_{111(2 \mathrm{OH})}\right] \mathrm{Cl}$ mole ratio obtained for both "DES" and PPG rich phases. The number of moles of each DES component in each phase, as well as mole ratio 

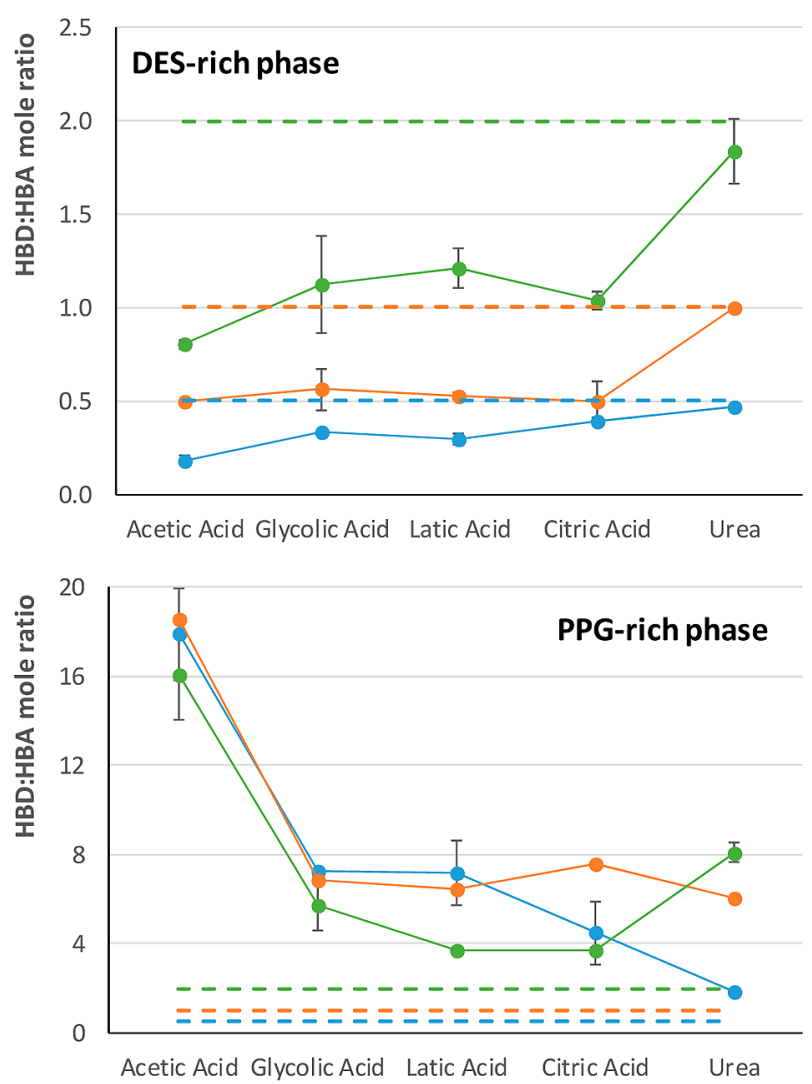

Figure 2. Mole ratio between the $\mathrm{HBD}$ and $\left[\mathrm{N}_{111(2 \mathrm{OH})}\right] \mathrm{Cl}(\mathrm{HBA})$ in the coexisting phases of ABS composed of DES + PPG $+\mathrm{H}_{2} \mathrm{O}$ (solid lines) and in DES initial composition (dashed lines): 1:2 (blue), 1:1 (orange), 2:1 (green).

between the HBD and HBA species, are presented in the Supporting Information. These results reveal that the carboxylic acid: $\left[\mathrm{N}_{111(2 \mathrm{OH})}\right] \mathrm{Cl}$ complexes are destroyed, since the ratio used on DES preparation is not maintained in the coexisting phases of DES based ABS. This nonstoichiometric partitioning of the DES components also reinforces the hypothesis that these $\mathrm{ABS}$ are formed by the salting out effect exerted by $\left[\mathrm{N}_{111(2 \mathrm{OH})}\right] \mathrm{Cl}$ over the polymer in aqueous media, since the formation of two phase systems was always observed. As previously highlighted, carboxylic acids slightly affect the solubility curves; however, they partition in different amounts between the coexisting phases. The extent of their partition is presented in the Supporting Information. Although more than $40 \%$ of carboxylic acids remain in the "DES" rich phase, in the PPG rich phase the amount of carboxylic acids is considerably higher than that of $\left[\mathrm{N}_{111(2 \mathrm{OH})}\right] \mathrm{Cl}$. In summary, there are no "real" DES based ABS. There are, on the other hand, ABS formed by $\left[\mathrm{N}_{111(2 \mathrm{OH})}\right] \mathrm{Cl}$ and PPG, where carboxylic acids seem to act as additives and tend to partition to different extents (according to the acid nature) between the coexisting phases.

The water effect on the DES integrity is one of the major gaps in the DES research field. The observed nonstoichiometric partition of the DES components between the coexisting phases reveals that the DES integrity is destroyed in an ABS by the disruption of the hydrogen bonding interactions within the HBD:HBA complex. These results are further corroborated by some recent works ${ }^{27-31}$ which demonstrated that the dilution of DES in water results in a progressive rupture of the hydrogen bonds between the starting materials. For each DES, there seems to exists a maximum amount of water that can be added before the complete disruption of the DES complex followed by the formation of an aqueous solution containing the solvated individual components.

On the basis of the results reported here, it can be concluded that ABS composed of carboxylic acid based DES are indeed quaternary systems and not ternary systems as other types of ABS. The formation of the ABS seems to be controlled by PPG 400 and $\left[\mathrm{N}_{111(2 \mathrm{OH})}\right] \mathrm{Cl}$, with a minor effect of the carboxylic acids. There are no "real" DES based ABS; instead, these systems are ABS formed by $\left[\mathrm{N}_{111(2 \mathrm{OH})}\right] \mathrm{Cl}$ and PPG 400, as previously reported, ${ }^{26}$ where the carboxylic acid acts as a fourth compound or additive in the ABS. ${ }^{32-34}$

The interactions between carboxylic acids and $\left[\mathrm{N}_{111(2 \mathrm{OH})}\right] \mathrm{Cl}$ are weaker than those observed in DES constituted by urea and $\left[\mathrm{N}_{111(2 \mathrm{OH})}\right] \mathrm{Cl}^{1}{ }^{1}$ As a further confirmation test, ABS composed of the DES formed by urea: $\left[\mathrm{N}_{111(2 \mathrm{OH})}\right] \mathrm{Cl}$ (at the mole composition ratios of $1: 2,1: 1$, and 2:1) and PPG 400 were also studied. The detailed experimental weight fraction data, respective phase diagrams, and compositions of the phases are presented in the Supporting Information. As observed with the ABS formed by carboxylic acids: $\left[\mathrm{N}_{111(2 \mathrm{OH})}\right] \mathrm{Cl} \mathrm{DES}, \mathrm{PPG}$ is salted out by $\left[\mathrm{N}_{111(2 \mathrm{OH})}\right] \mathrm{Cl}$, while urea has a negligible effect on the phase diagram behavior. However, unlike for the other systems discussed above, the urea: $\left[\mathrm{N}_{111(2 \mathrm{OH})}\right] \mathrm{Cl}$ mole ratio in the "DES" rich phase depicted in Figure 2 is the same as the initial mole ratio used in the DES preparation. The question of the stability of this particular DES complex is thus not settled by the results reported here. A finer analysis of these results is thus in order. From all HBD species studied in this work, urea presents the lowest octanol-water partition coefficient $\left(K_{\mathrm{OW}}\right)$, thus presenting a higher affinity for salt aqueous rich phases when compared with the carboxylic acids. Contrary to that observed for carboxylic acids, the extraction efficiency of urea is higher than $90 \%$ meaning that most urea on the system remains in the cholinium rich phase; the number of moles of each species in each phase is provided in the Supporting Information. Since PPG aqueous rich phases are composed of a large amount of polymer ( $>70$ wt $\%$ from tie lines data, cf. Supporting Information), with only a small amount of water and other components, the distribution data obtained by ${ }^{1} \mathrm{H}$ NMR spectroscopy for the coexisting phases of the urea: $\left[\mathrm{N}_{111(2 \mathrm{OH})}\right] \mathrm{Cl}$ based $\mathrm{ABS}$ could be a result of the almost total partition of both the $\left[\mathrm{N}_{111(2 \mathrm{OH})}\right] \mathrm{Cl}$ and urea to the most hydrophilic phase, which would explain the results obtained (cf. Supporting Information). In fact, literature results ${ }^{27-31}$ support the idea that this complex is not stable at water concentrations higher than 50 wt \% (cf. Supporting Information), as those observed in the "DES" rich phase of our systems. Overall, the obtained results suggest that DES based ABS are quaternary systems composed of $\left[\mathrm{N}_{111(2 \mathrm{OH})}\right] \mathrm{Cl}, \mathrm{PPG} 400$, and water, with carboxylic acids or urea acting as additives.

Although ABS composed of DES are quaternary instead of ternary systems, their applicability may not be conditioned by the DES nonstoichiometric partitioning. To demonstrate their potential in separation processes, the selective extraction of two textile dyes, namely, pigment blue (PB29) and Sudan III, was evaluated, Figure 3. Mixture compositions and extraction efficiencies $\left(\mathrm{EE}_{\mathrm{dye}} \%\right)$ are described in detail in the Supporting Information. In all DES based ABS, Sudan III preferentially partitions to the PPG rich phase, while PB 29 completely migrates to the opposite phase. Sudan III has a less polar character $\left(\log \left(K_{\mathrm{OW}}\right)=7.74\right)^{35}$ than PB29 and therefore 


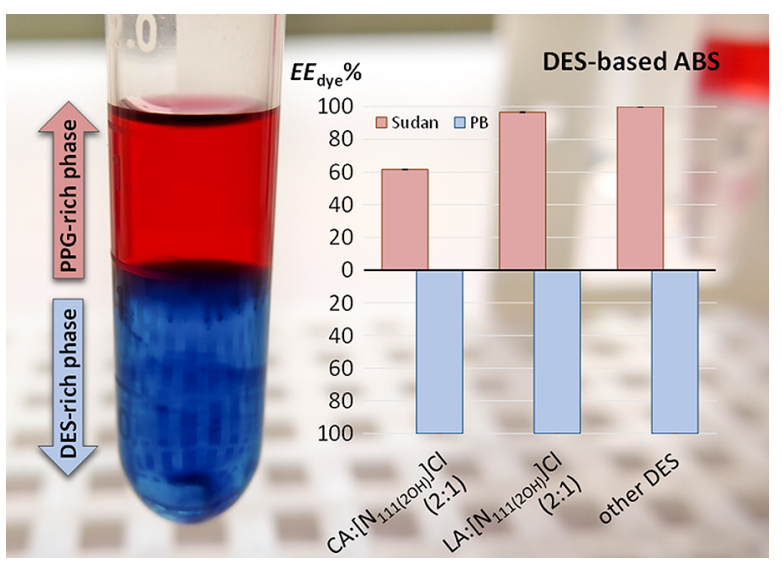

Figure 3. Selective extraction of the textile dyes Sudan III and PB 29 with ABS composed of DES.

preferentially partitions to the more hydrophobic PPG rich phase, while the inorganic pigment partitions to the more polar salt rich phase.

Remarkably, for 10 of the 12 studied systems, the complete separation of the two dyes was achieved; i.e., they are completely enriched in one of the phases. Only the systems composed of citric acid: $\left[\mathrm{N}_{111(2 \mathrm{OH})}\right] \mathrm{Cl}(2: 1)$ and lactic acid: $\left[\mathrm{N}_{111(2 \mathrm{OH})}\right] \mathrm{Cl}(2: 1)$ display lower extraction efficiencies for Sudan III, $61.6 \%$ and $96.6 \%$, respectively (Figure 3 ). The worst performance of these two systems seems to be related to their lower ability to create ABS. Furthermore, the extraction performance of DES based ABS is identical to that of IL based $\mathrm{ABS}$ formed by $\left[\mathrm{N}_{111(2 \mathrm{OH})}\right]$ based ILs, $\left[\mathrm{N}_{111(2 \mathrm{OH})}\right] \mathrm{Cl}$, $\left[\mathrm{N}_{111(2 \mathrm{OH})}\right][\mathrm{Ace}], \quad\left[\mathrm{N}_{111(2 \mathrm{OH})}\right][\mathrm{Gly}], \quad\left[\mathrm{N}_{111(2 \mathrm{OH})}\right][\mathrm{Lac}]$, and $\left[\mathrm{N}_{111(2 \mathrm{OH})}\right][\mathrm{DHC}]$, and PPG 400 (cf. the Supporting Information), wich means that DES based ABS are able to compete in terms of extraction performance with IL based systems. Nevertheless, contrary to IL based ABS, the presence of volatile acids and the nonstoichiometric partition of the DES isolated components between the coexisting phases makes the design of a sustainable process more difficult, particularly when the recovery and recycling of the phase forming components is envisaged. For instance, two approaches were previously proposed by Ferreira et al. ${ }^{36}$ for the recovery of textile dyes (by induced precipitation) from the coexisting phases of ABS composed of ILs and salts by a reduction in temperature or by water evaporation, which further permits the recycling of the phase forming components. In DES based ABS, the presence of volatile acids and the nonstoichiometric partition of the DES isolated components between the coexisting phases require the design of more complex recovery processes.

In summary, the results reported here demonstrate that the DES integrity is destroyed in ABS by the disruption of the DES hydrogen bond complex and preferential solvation of the isolated components by water. This is confirmed by the nonstoichiometric partition of the HBD and HBA species between the coexisting phases supporting the idea that DES based $A B S$ are in fact quaternary instead of ternary systems. These ABS are formed by $\left[\mathrm{N}_{111(2 \mathrm{OH})}\right] \mathrm{Cl}$ and PPG 400 in water, where the carboxylic acids or urea act as the fourth component or an additive in the overall system. It was also shown that DES based ABS have potential to be used in extraction and purification processes, as it is here demonstrated with the complete separation of two dyes for opposite phases in a single step. However, it should be kept in mind that the non stoichiometric partition of the DES components and the volatile nature of short chain carboxylic acids make the design of an integrated and sustainable separation process more complex than that required, for instance, with IL based ABS. ${ }^{36}$

\section{ASSOCIATED CONTENT}

\section{Supporting Information}

The Supporting Information is available free of charge on the ACS Publications website at DOI: 10.1021/acssusche meng.6b00485.

Detailed experimental data of binodal curves, DES stability, and textile dyes extraction efficiencies (PDF)

\section{AUTHOR INFORMATION}

\section{Corresponding Author}

*E mail: jcoutinho@ua.pt. Fax: +351 234370084. Phone: +351 234401507.

\section{Notes}

The authors declare no competing financial interest.

\section{ACKNOWLEDGMENTS}

This work was developed within the scope of the project CICECO Aveiro Institute of Materials, POCI 010145 FEDER 007679 (FCT ref. UID/CTM/50011/2013), financed by national funds through the FCT/MEC and when appropriate cofinanced by FEDER under the PT2020 Partner ship Agreement. The authors also acknowledge FCT for the doctoral grants SFRH/BD/85248/2012 and SFRH/BD/ 92200/2013 of H.P. and A.M.F., respectively.

\section{REFERENCES}

(1) Abbott, A. P.; Capper, G.; Davies, D. L.; Rasheed, R. K.; Tambyrajah, V. Novel solvent properties of choline chloride/urea mixtures. Chem. Commun. 2003, 1, 70-71.

(2) Paiva, A.; Craveiro, R.; Aroso, I.; Martins, M.; Reis, R. L.; Duarte, A. R. C. Natural deep eutectic solvents - Solvents for the 21 st century. ACS Sustainable Chem. Eng. 2014, 2 (5), 1063-1071.

(3) Francisco, M.; van den Bruinhorst, A.; Kroon, M. C. Low transition temperature mixtures (LTTMs): a new generation of designer solvents. Angew. Chem., Int. Ed. 2013, 52 (11), 3074-3085.

(4) Smith, E. L.; Abbott, A. P.; Ryder, K. S. Deep eutectic solvents (DESs) and their applications. Chem. Rev. 2014, 114 (21), 1106011082.

(5) Abbott, A. P.; Capper, G.; Davies, D. L.; Munro, H. L.; Rasheed, R. K.; Tambyrajah, V. Preparation of novel, moisture stable, Lewis acidic ionic liquids containing quaternary ammonium salts with functional side chains. Chem. Commun. 2001, 19, 2010-2011.

(6) Wasserscheid, P.; Keim, W. Ionic liquids New "solutions" for transition metal catalysis. Angew. Chem., Int. Ed. 2000, 39 (21), 37723789.

(7) Welton, T. Room temperature ionic liquids. Solvents for synthesis and catalysis. Chem. Rev. 1999, 99 (8), 2071-2084.

(8) Florindo, C.; Oliveira, F. S.; Rebelo, L. P. N.; Fernandes, A. M.; Marrucho, I. M. Insights into the synthesis and properties of deep eutectic solvents based on cholinium chloride and carboxylic acids. ACS Sustainable Chem. Eng. 2014, 2 (10), 2416-2425.

(9) Choi, Y. H.; van Spronsen, J.; Dai, Y.; Verberne, M.; Hollmann, F.; Arends, I. W. C. E.; Witkamp, G. J.; Verpoorte, R. Are natural deep eutectic solvents the missing link in understanding cellular metabolism and physiology? Plant Physiol. 2011, 156, 1701-1705.

(10) Kareem, M. A.; Mjalli, F. S.; Hashim, M. A.; AlNashef, I. M. Phosphonium based ionic liquids analogues and their physical properties. J. Chem. Eng. Data 2010, 55 (11), 4632-4637.

(11) Abbott, A. P.; Boothby, D.; Capper, G.; Davies, D. L.; Rasheed, R. K. Deep eutectic solvents formed between choline chloride and 
carboxylic acids: versatile alternatives to ionic liquids. J. Am. Chem. Soc. 2004, 126 (29), 9142-9147.

(12) Francisco, M.; van den Bruinhorst, A.; Kroon, M. C. New natural and renewable low transition temperature mixtures (LTTMs): screening as solvents for lignocellulosic biomass processing. Green Chem. 2012, 14 (8), 2153-2157.

(13) Gállego, I.; Grover, M. A.; Hud, N. V. Folding and imaging of DNA nanostructures in anhydrous and hydrated deep eutectic solvents. Angew. Chem. 2015, 127 (23), 6869-6873.

(14) Vidal, C.; García Álvarez, J.; Hernán Gómez, A.; Kennedy, A. R.; Hevia, E. Introducing deep eutectic solvents to polar organometallic chemistry: chemoselective addition of organolithium and grignard reagents to ketones in air. Angew. Chem., Int. Ed. 2014, 53 (23), 59695973.

(15) Wang, H.; Gurau, G.; Shamshina, J.; Cojocaru, O. A.; Janikowski, J.; MacFarlane, D. R.; Davis, J. H.; Rogers, R. D. Simultaneous membrane transport of two active pharmaceutical ingredients by charge assisted hydrogen bond complex formation. Chemical Science 2014, 5 (9), 3449-3456.

(16) Freire, M. G.; Cláudio, A. F. M.; Araújo, J. M. M.; Coutinho, J. A. P.; Marrucho, I. M.; Canongia Lopes, J. N.; Rebelo, L. P. N. Aqueous biphasic systems: a boost brought about by using ionic liquids. Chem. Soc. Rev. 2012, 41, 4966-4995.

(17) Xu, K.; Wang, Y.; Huang, Y.; Li, N.; Wen, Q. A green deep eutectic solvent based aqueous two phase system for protein extracting. Anal. Chim. Acta 2015, 864, 9-20.

(18) Zeng, Q.; Wang, Y.; Huang, Y.; Ding, X.; Chen, J.; Xu, K. Deep eutectic solvents as novel extraction media for protein partitioning. Analyst 2014, 139 (10), 2565-2573.

(19) Wu, C.; Wang, J.; Pei, Y.; Wang, H.; Li, Z. Salting out effect of ionic liquids on poly(propylene glycol) (PPG): formation of PPG + ionic liquid aqueous two phase systems. J. Chem. Eng. Data 2010, 55 (11), 5004-5008.

(20) Zafarani Moattar, M. T.; Hamzehzadeh, S.; Nasiri, S. A new aqueous biphasic system containing polypropylene glycol and a water miscible ionic liquid. Biotechnol. Prog. 2012, 28 (1), 146-156.

(21) Muhammad, N.; Hossain, M. I.; Man, Z.; El Harbawi, M.; Bustam, M. A.; Noaman, Y. A.; Mohamed Alitheen, N. B.; Ng, M. K.; Hefter, G.; Yin, C. Y. Synthesis and physical properties of choline carboxylate ionic liquids. J. Chem. Eng. Data 2012, 57 (8), 2191-2196.

(22) Pernak, J.; Syguda, A.; Mirska, I.; Pernak, A.; Nawrot, J.; Prądzyńska, A.; Griffin, S. T.; Rogers, R. D. Choline derivative based ionic liquids. Chem. Eur. J. 2007, 13 (24), 6817-6827.

(23) Neves, C. M. S. S.; Ventura, S. P. M.; Freire, M. G.; Marrucho, I. M.; Coutinho, J. A. P. Evaluation of cation influence on the formation and extraction capability of ionic liquid based aqueous biphasic systems. J. Phys. Chem. B 2009, 113, 5194-5199.

(24) Ventura, S. P. M.; Neves, C. M. S. S.; Freire, M. G.; Marrucho, I. M.; Oliveira, J.; Coutinho, J. a. P. Evaluation of anion influence on the formation and extraction capacity of ionic liquid based aqueous biphasic systems. J. Phys. Chem. B 2009, 113, 9304-9310.

(25) Mourão, T.; Cláudio, A. F. M.; Boal Palheiros, I.; Freire, M. G.; Coutinho, J. A. P. Evaluation of the impact of phosphate salts on the formation of ionic liquid based aqueous biphasic systems. J. Chem. Thermodyn. 2012, 54, 398-405.

(26) Quental, M. V.; Caban, M.; Pereira, M. M.; Stepnowski, P.; Coutinho, J. A. P.; Freire, M. G. Enhanced extraction of proteins using cholinium based ionic liquids as phase forming components of aqueous biphasic systems. Biotechnol. J. 2015, 10, 1457-1466.

(27) D’Agostino, C.; Gladden, L. F.; Mantle, M. D.; Abbott, A. P.; Ahmed, E. I.; Al Murshedi, A. Y. M.; Harris, R. C. Molecular and ionic diffusion in aqueous deep eutectic solvent mixtures: probing inter molecular interactions using PFG NMR. Phys. Chem. Chem. Phys. 2015, 17 (23), 15297-15304.

(28) Dai, Y.; van Spronsen, J.; Witkamp, G. J.; Verpoorte, R.; Choi, Y. H. Natural deep eutectic solvents as new potential media for green technology. Anal. Chim. Acta 2013, 766, 61-68.
(29) Dai, Y.; Witkamp, G. J.; Verpoorte, R.; Choi, Y. H. Tailoring properties of natural deep eutectic solvents with water to facilitate their applications. Food Chem. 2015, 187, 14-19.

(30) Gutiérrez, M. C.; Ferrer, M. L.; Mateo, C. R.; del Monte, F. Freeze drying of aqueous solutions of deep eutectic solvents: a suitable approach to deep eutectic suspensions of self assembled structures. Langmuir 2009, 25 (10), 5509-5515.

(31) Shah, D.; Mjalli, F. S. Effect of water on the thermo physical properties of Reline: An experimental and molecular simulation based approach. Phys. Chem. Chem. Phys. 2014, 16 (43), 23900-23907.

(32) Almeida, M. R.; Passos, H.; Pereira, M. M.; Lima, Á. S.; Coutinho, J. A. P.; Freire, M. G. Ionic liquids as additives to enhance the extraction of antioxidants in aqueous two phase systems. Sep. Purif. Technol. 2014, 128, 1-10.

(33) de Souza, R. L.; Campos, V. C.; Ventura, S. P. M.; Soares, C. M. F.; Coutinho, J. A. P.; Lima, Á. S. Effect of ionic liquids as adjuvants on PEG based ABS formation and the extraction of two probe dyes. Fluid Phase Equilib. 2014, 375, 30-36.

(34) Pereira, J. F. B.; Lima, A. S.; Freire, M. G.; Coutinho, J. A. P. Ionic liquids as adjuvants for the tailored extraction of biomolecules in aqueous biphasic systems. Green Chem. 2010, 12 (9), 1661-1669.

(35) ChemSpider-Search and Share Chemistry; http://www. chemspider.com (accessed August 2015).

(36) Ferreira, A. M.; Coutinho, J. A. P.; Fernandes, A. M.; Freire, M. G. Complete removal of textile dyes from aqueous media using ionic liquid based aqueous two phase systems. Sep. Purif. Technol. 2014, 128, $58-66$. 